Table S2. Identification data of the proteins listed in Table 2.

\title{
A $\beta$-GFP
}

Mass-spectrum (MS/MS):
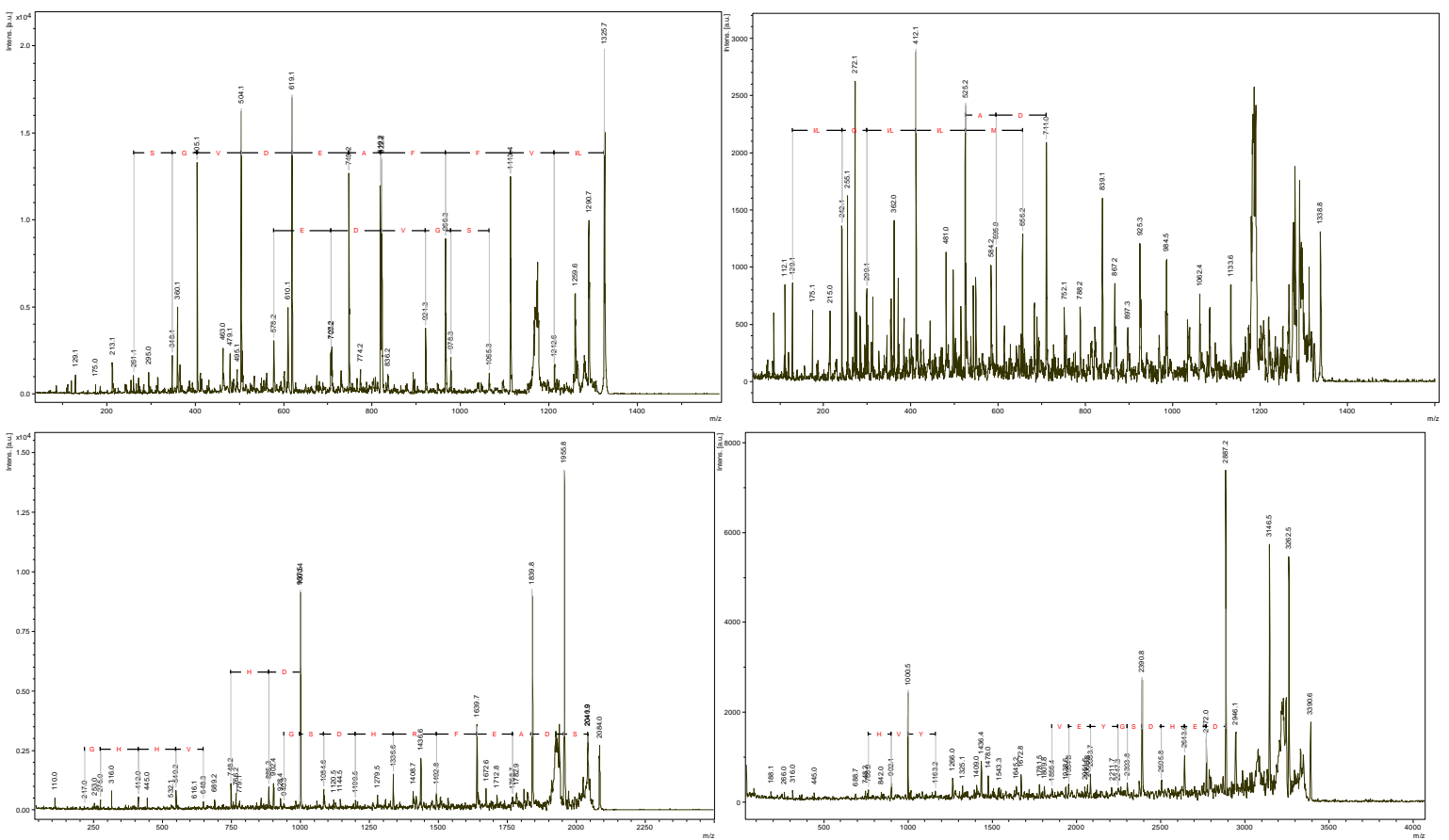

Identification:

gi|253723204 Mass: 2176

Score: 137

Matches: $1(1)$ Sequences: $1(1)$

Chain A, Zinc-Binding Domain Of Alzheimer's Disease Amyloid Beta- Peptide In Water Solution At $\mathrm{Ph} 6.5$

Query Observed Mr (expt) Mr(calc) ppm Miss Score Expect Rank Unique Peptide

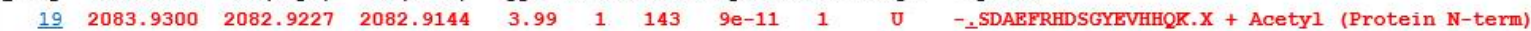

gi|177958
amyloid beta protein,
amartial [Homo sapiens]

Matches: $1(1)$ Sequences: $1(1)$

\begin{tabular}{|c|c|c|c|c|c|c|c|c|c|c|}
\hline Query & Observed & $M r(\exp t)$ & Mr (calc) & ppm & Miss & Score & Expect & Rank & Unique & Peptide \\
\hline$\underline{8}$ & 1325.6741 & 1324.6668 & 1324.6663 & 0.39 & 0 & 98 & $5.5 e-06$ & 1 & U & K. LVFFAED \\
\hline
\end{tabular}




\section{PrP-GFP}

\section{Mass-spectrum:}

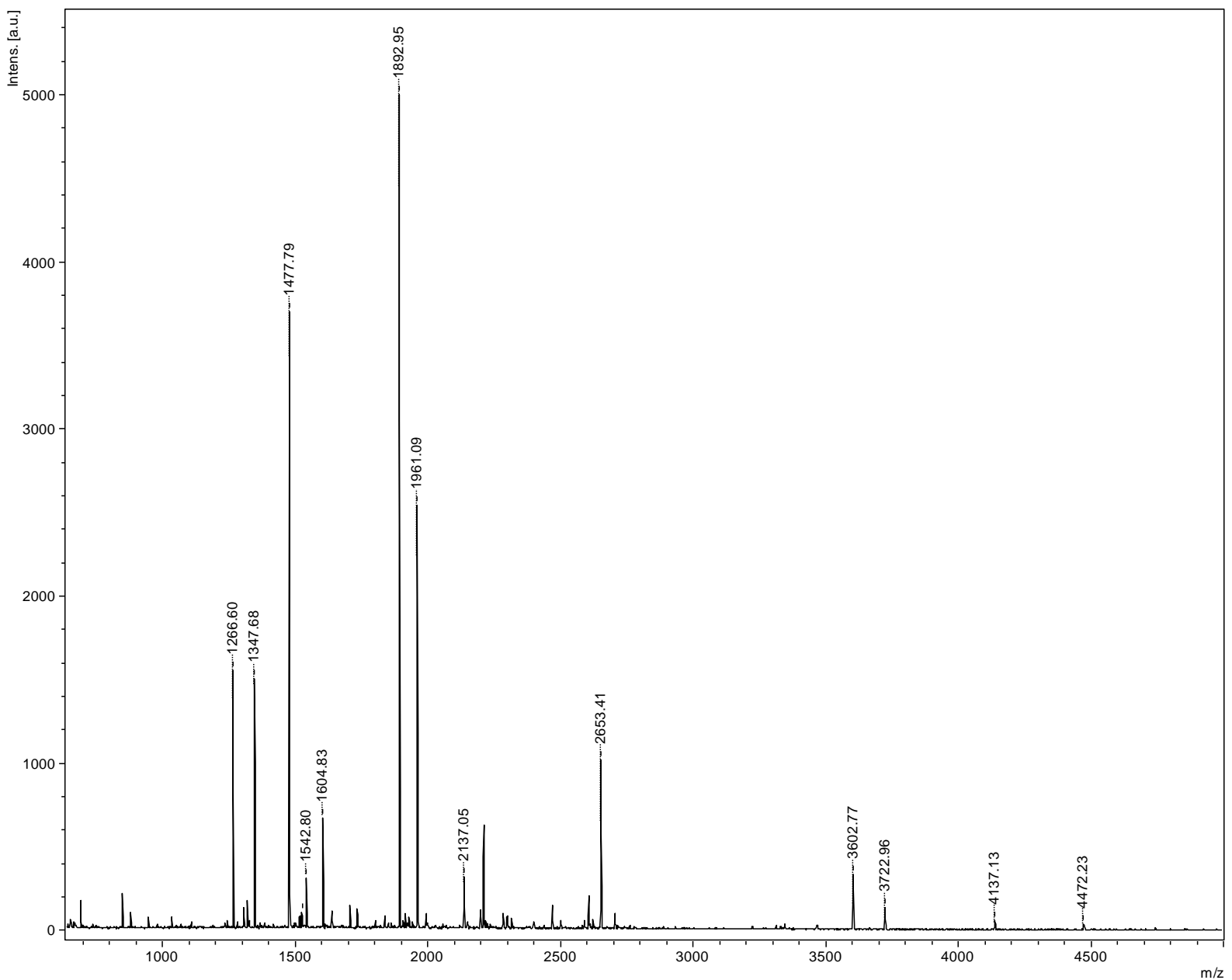

Identification:

gi| 240104235

Mass: 13201

Score: 310

Expect: $2.7 e-24$ Matches: 4

Chain A, Mouse Prion Protein (121-231) With Mutations Y225a And Y226a

Observed $\mathrm{Mr}$ (expt) $\mathrm{Mr}$ (calc) ppm Start End Miss Ions Peptide

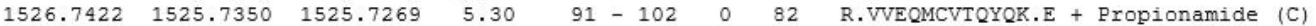

1542.7988 $1541.7915 \quad 1541.7218 \quad 45.2 \quad 91$ - $102 \quad 0 \quad---\quad$ R.VVEQMCVTQYQR.E + Oxidation (M); Propionamide (C)

$\begin{array}{lllllllll}2137.0502 & 2136.0430 & 2136.0335 & 4.42 & 68 & -86 & 1 & 141 & \text { K.QHTVTTTTKGENFTETDVK.M }\end{array}$

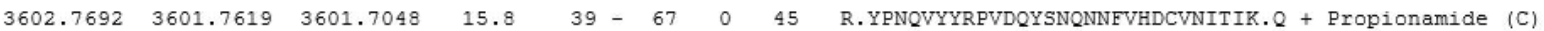

No match to: $1266.5968,1347.6805,1477.7942,1604.8267,1892.9471,1961.0884,2653.4058,3722.9558,4137.1268$, 4472.2296 


\section{Rnq1}

Mass-spectrum:

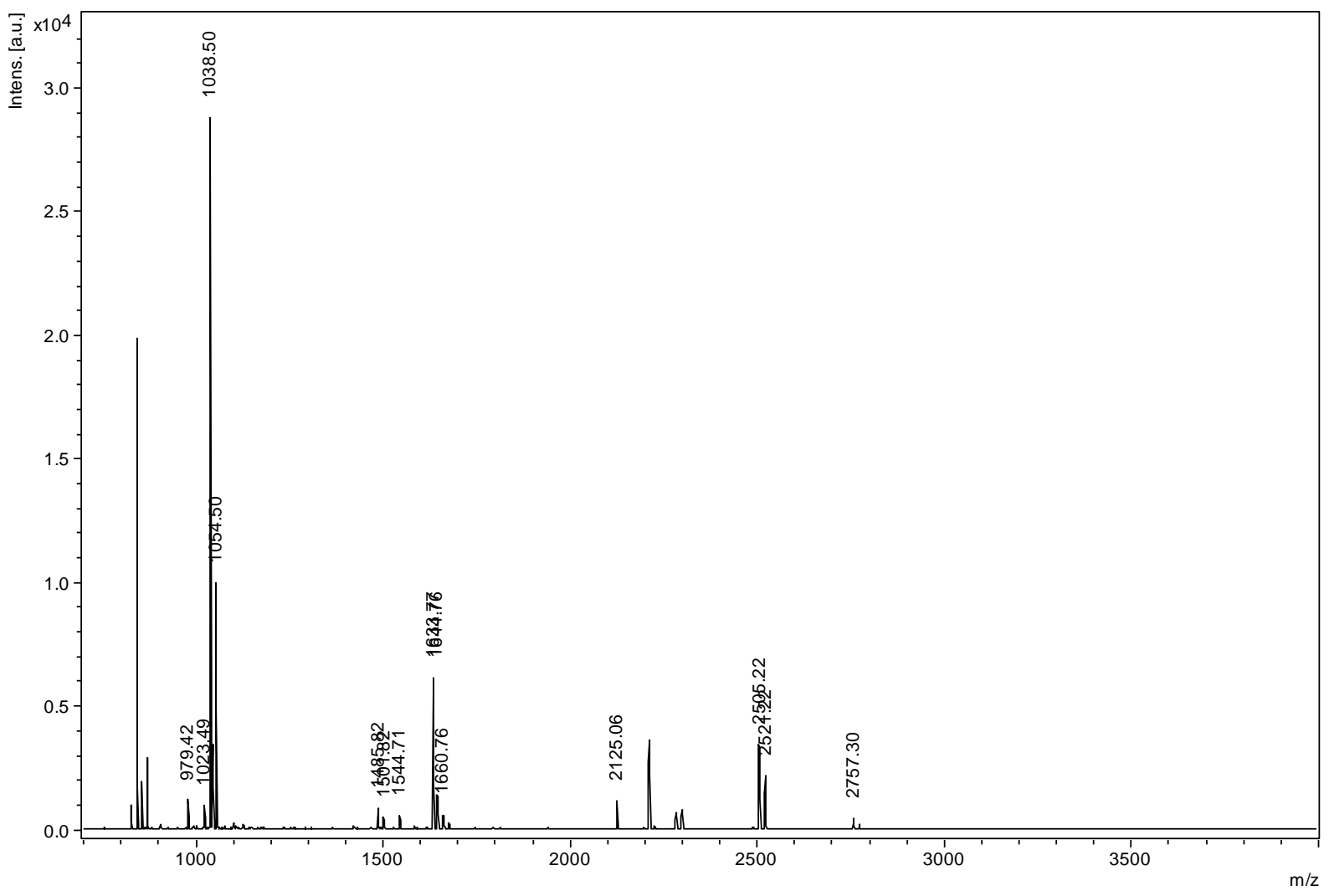

Identification:

gi|408368764 Mass: $18836 \quad$ Score: 94

Expect: 0.0091 Matches: 10

truncated Rnqlp [Saccharomyces cerevisiae]

\begin{tabular}{|c|c|c|c|c|c|c|c|c|}
\hline Observed & $\operatorname{Mr}(\exp t)$ & $\mathrm{Mr}(\mathrm{calc})$ & ppm & Start & & End & Miss & Peptide \\
\hline 979.4196 & 978.4123 & 978.4003 & 12.3 & 58 & - & 67 & 0 & R.SGGSDASQDR.A \\
\hline 1038.5017 & 1037.4944 & 1037.4964 & -1.90 & 49 & - & 57 & 0 & K.IAGYVMDNR.S \\
\hline 1054.5032 & 1053.4959 & 1053.4913 & 4.39 & 49 & - & 57 & 0 & K.IAGYMMDR.S + Oxidation (M) \\
\hline 1501.8173 & 1500.8100 & 1500.7970 & 8.67 & 94 & - & 107 & 0 & K.LALLATVMTHSSNK.G + Oxidation (M) \\
\hline 1644.7597 & 1643.7525 & 1643.7283 & 14.7 & 68 & - & 84 & 0 & R.AAGGGSSFMNTLMADSK.G \\
\hline 2505.2183 & 2504.2110 & 2504.2064 & 1.85 & 26 & - & 48 & 0 & K.LTSAAQSNPNDEQMSTIESLIQK. I \\
\hline 2521.2183 & 2520.2111 & 2520.2013 & 3.86 & 26 & - & 48 & 0 & K.LTSAAQSNPNDEQMSTIESLIQK.I + Oxidation (M) \\
\hline
\end{tabular}

